(Resubmitted to the Journal of Physical Chemistry, July 2003)

\title{
COMPARISON OF EXPERIMENTAL AND THEORETICAL HETEROGENEOUS NUCLEATION ON ULTRAFINE CARBON PARTICLES
}

\author{
Doh-Won Lee ${ }^{1}$, Philip K. Hopke ${ }^{1 *}$, Don H. Rasmussen ${ }^{1}$, Hwa-Chi Wang ${ }^{2,3}$, Rashid Mavliev ${ }^{2}$ \\ 1) Clarkson University, Potsdam, NY \\ 2) Illinois Institute of Technology, Chicago, IL \\ 3) Air Liquide, Chicago Research Center, Countryside, IL
}

\begin{abstract}
Using a modified Turbulent Mixing CNC, the heterogeneous nucleation of different compounds (working fluids) on nanometer sized carbon particles was examined. The working fluids were dibutyl phthalate, octadecane, octadecanol, and octadecanoic acid. Based on the particle size distributions measured with a scanning mobility particle sizer system, nucleation and consequent growth were examined with respect to different temperature and vapor pressure for each working fluid. Nucleation rates for all conditions were calculated from the fitted size distribution data by subtracting the residual nonactivated particle concentration for each condition. Experimental nucleation rates were compared to the calculated ones based on Fletcher's heterogeneous nucleation theory. This theory matches well with the experiments with octadecanol and octadecanoic acid, and at high supersaturation ratios for dibutyl phthalate. However, the theory shows discrepancies with the observed phenomena at low supersaturation for dibutyl phthalate, and especially for octadecane. Several possible hypotheses for the discrepancies and observed particle growth are discussed.
\end{abstract}

Keywords: heterogeneous nucleation, ultrafine carbon particles, octadecane, octadecanol, octadecanoic acid, dibutyl phthalate

\footnotetext{
*__ Seaton, A., MaeNee, W., Donattson, K., and Godden, D. Lancet, 1995, 345, 176-178 (1995). Author to whom correspondences should be addressed: hopkepk@ clarkson.edu; $\underline{\underline{\text { fax: } 3152684410}}$
} 
(Stbmitted to the Journat of Physicat Chemistry, Deeember 2002)

EOMPARISONOFEXPERMMENTAL AND THEORETHCAL HETEROGENEOUS

NUCLEATIONON ULTRAFINE PARTICLES

Đoh-Won Lee ${ }^{\dagger}$, Philip K. Hopke ${ }^{\dagger}$, Don H. Rasmussen ${ }^{\dagger}$, Hwa-Chi Wang ${ }^{2,3}$, Rashid Mavliev ${ }^{2}$

1) Clarkson University, Potsdam, NY

z) fllinois Instittte of Teehnology, Chieago, \#

3) Air tiquide, Chieago Researeh Center, Countryside, It

\section{ABSTRACT}

Using a modified Turbutent Mixing CNC, the heterogeneous nueleation of different compounds (working fluids) on nanometer sized earbon partieles was examined. The working fluids were dibutyl phthalate, oetadeeane, oetadeeanol, and oetadeeanoie aeid. Based on the partiele size distributions measured with a seanning mobility partiele sizer system, nueleation and consequent grow th were examined with respeet to different temperature and vapor pressure for each working fluid. Nuteation rates for alleonditions were eatetlated from the fitted size distribution data by stbtraeting the residual nonaetivated partiele coneentration for each eondition. Experimentat ntteleation rates were empared to the ealettated ones based on Fleteher's heterogeneous ntueleation theory. This theory matehes well with the experiments with oetadeeanol and oetadeeanoie aeid, and at high supersaturation ratios for dibutyl phthalate. However, the theory shows diserepaneies with the observed phenomena at low supersaturation for dibutyl phthalate, and especially for oetadeeane. Severat possible hypotheses for the diserepaneies and observed partiele grow thare disetrsset.

\section{INTRODUCTION}


Attention has now focused on the ultrafine fraction of the ambient aerosol. Ultrafine particles have been proposed as a major factor contributing to the adverse health effects of particulate air pollution $[1,2]$. To characterize these ultrafine particles, systems have been developed in which the particles are nucleated with water vapor and grown to sizes where they can be-collected by inertia $[3,4,5]$. Thus, understanding heterogeneous nucleation has becomes more important in a number of researeh areas.

Although possible formation mechanisms for these small particles are discussed in the literature, complete theoretical models are not yet available. One main reason is complexity of the atmospheric system. Any simplified description can only be proposed based on a solid experimental foundation. However, limited experimental methods are available to investigate particle formation processes even in model systems.

Prior to developing better theoretical models through ideal experiments, measurements of the nucleation behavior of model compounds onto carbon particles were performed to examine the relationship between molecular properties of the condensing vapor (working fluid) and the particles. The experimental results were converted to experimental nucleation rates for the comparison with theoretitesthe ones calculated with well-known Fletcher's heterogeneous nucleation theory [6]. In this paper, the results of such experiments are presented along with several hypotheses introduced to explain the discrepancies between the experiment and the theory. These hypotheses may enhance current limited theoretical understanding of heterogeneous nucleation described in the next section and provide useful insights into the nature of the processes involved.

\section{THEORETICAL BACKGROUND}

There has been continued interest in developing an accurate nucleation theory since the early work of Volmer and Weber [7]. According to Wu [8], Volmer [9] defined the simplest model for the heterogeneous nucleation with the assumption that mptrities loelly flatimpurity surfaces permit liquid cluster growth as spherical caps with constant wetting angle $\theta$ (Figure 1).

In most cases, the surface of a substrate should not be considered to be flat. It should be treated as a convex surface especially for nanometer size heterogeneous nuclei-(Figure 2). The 
Gibbs free energy for heterogeneous nucleation is expressed as:

$\Delta G=\left(\frac{\mu_{l}-\mu_{g}}{\Omega}\right) V_{l}+\gamma_{g l} A_{g l}+\left(\gamma_{l s}-\gamma_{g s}\right) A_{l s}$

in which $\mu_{1}$ and $\mu_{\mathrm{g}}$ are, respectively, the chemical potential of the liquid and gas phase, $\Omega$ is the average volume per monomer in the bulk liquid, $V_{1}$ is the liquid volume, $\gamma_{i j}$ is the macroscopic surface energy per unit area of $\mathrm{i}-\mathrm{j}$ interface, and $\mathrm{A}_{\mathrm{ij}}$ denotes the interfacial surface area of the $\mathrm{I}-\mathrm{j}$ interface, respectively. Referring to Figure 2,

$V_{l}=\frac{1}{3} \pi r^{3}\left(2-3 \cos \psi+\cos ^{3} \psi\right)-\frac{1}{3} \pi a^{3}\left(2-3 \cos \varphi+\cos ^{3} \varphi\right)$,

$A_{g l}=2 \pi r^{2}(1-\cos \psi)$,

$A_{l s}=2 \pi a^{2}(1-\cos \varphi)$,

and

$\cos \psi=-(r-a \cos \theta) / d=-(r-a m) / d$,

$\cos \varphi=(a-r \cos \theta) / d=(a-r m) / d$,

where $d=\left(a^{2}+r^{2}-2 a r m\right)^{1 / 2}$ with $m=\cos \theta=\left(\gamma_{g s}-\gamma_{l s}\right) / \gamma_{g l}$.

The symbols, $r$ and a, used in equations (2) and (3) are the radii of the condensing cluster and the heterogeneous nuclei particle, respectively.

Setting $\partial \mathrm{G} / \partial \mathrm{r}=0$, and solving the resulting Equation (1) in combination with the Equations (2) and (3), Fletcher [6] showed that the equation for the critical radius $r^{*}$ is $r^{*}=-2 \gamma_{g l} / \Delta G_{v}$

where $\Delta \mathrm{G}_{\mathrm{v}}$ is $-\mathrm{k}_{\mathrm{B}} \mathrm{T} \ln \mathrm{S} / \Omega$, in which $\mathrm{k}_{\mathrm{B}}$ is Boltzmann constant, $\mathrm{T}$ is temperature, and $\mathrm{S}$ is the $\underline{\underline{\text { supersaturation ratio, } \mathrm{S}=\mathrm{P} / \mathrm{P}}}$ sat $\underline{\underline{\mathrm{T}}) \text {, the actual pressure of the monomer divided by its equilibrium }}$ vapor pressure at the temperature of interest.. Substituting Equations (2) to (4) into Equation (1) and letting $\mathrm{x}=\mathrm{a} / \mathrm{r}^{*}$, Fletcher [6] obtained the equation for the Gibbs free energy of formation of a critical embryo: 


$$
\Delta G^{*}=\frac{8 \pi \gamma_{g l}^{3}}{3\left(\Delta G_{v}\right)^{2}} f(m \cdot x),
$$

where

withr.

$\underline{\underline{\text { where }}}$

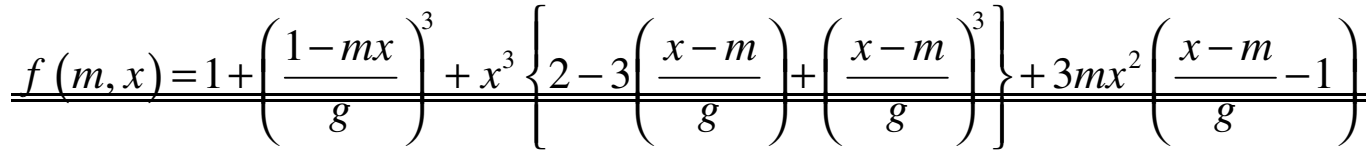

with $g=\left(1+x^{2}-2 m x\right)^{1 / 2}$.

At and above the given $\mathrm{S}$, the (pre-existing) heterogenous nuclei particle, having radius

of a, can have enough condensable monomers adsorbed on the surface to form a stable critical cluster, which is the process of heterogeneous nucleation. Below the given $\mathrm{S}$, less monomers can also be deposited to form a cluster, but these monomers will evaporate eventually because the decrease in free energy on association of these monomers is not sufficient to overcome the surface energy barrier to form the critical cluster. At a given S, particles having size of "a" or larger are activated by heterogeneous nucleation, and, then, undergo growth by condensation of more monomers onto this critical cluster while particles having a radius smaller than "a" in size are not activated and the monomers deposited on the surfaces eventually evaporate back to the gas phase.

In order to calculate the nucleation rate, classical theory involves several assumptions. First, it assumes that only a single monomer is added to or removed from the cluster in each step of the growth and evaporation process. The next assumption is that the sticking coefficient is 1 , so that the impingement rate is the number of collisions between monomers and an $n=-$ mer per unit time. Next, for the evaporation rate, the constrained equilibrium hypothesis is applied, which asserts that the metastable gas phase obeys the laws of fluctuation thermodynamics [8]. With the boundary condition that there is no monomer depletion, the steady state nucleation rate, $\mathrm{J}$, for the critical cluster is calculated by the steepest descent approximation. The resulting 
equation [8] for this convex spherical surface case is:

$\mid J \approx \frac{s(\theta)}{\sqrt{v(\theta)}} \sqrt{\frac{2 \Omega^{2} \gamma}{\pi m_{1}}} f_{1 \text { het }} f_{1}\left\{1+\left(n_{\text {hom }}\right)^{-1 / 3}\right\}^{2} \exp \left(\frac{-\Delta G^{*}}{k_{B} T}\right)$,

where $s(\theta)=(1-\cos \theta) / 2$ and $v(\theta)=V_{l} /\left(4 \pi r^{3} / 3\right)$

in which $\mathrm{s}(\theta)$ and $\mathrm{v}(\theta)$ are, respectively, the exposed surface and volume ratios relative to an entire projected sphere, $\gamma$ is the macroscopic surface energy per unit area at the liquid-gas interface, $\mathrm{m}_{1}$ is the mass of a monomer, $\mathrm{f}_{1}$ is the monomer concentration in the gas, $\mathrm{f}_{1 \text { het }}$ is the number concentration of existing nuclei, and the factor of $\left(1+n^{*}{ }_{\text {hom }}^{-1 / 3}\right)^{2}$ accounts for treating an $\mathrm{n}^{*}$-mer as a sphere rather than a flat surface.

The interactions between the nuclei and vapor molecules are likely to have a strong influence on the heterogeneous nucleation process. The formation energy of the working fluid embryo will involve the interaction of solid-liquid and liquid-gas interfaces. According to

| Fletcher $[z \underline{\underline{10}}]$, one of the most important parameters in this case is the contact angle between the particle surface and the condensed phase. However, the contact angle for nanometer size particles is not available and the contact angle of bulk material may not be valid. White [11] found appreciable differences between microscopic and macroscopic contact angles.

Experimental investigation of the effects of the nuclei composition on nucleation aetivation become extremely important. Nevertheless, very In addition to physical characterization, chemical characterization is the key to determine the role of the different particle formation processes as stated by Friedlander and Lippmann [12]. When nanometer size particles are of concern, near molecular scale chemical interactions probably need to be considered. Very little information is available in the literature. Helsper and Niessner [13] investigated the effect of the vapor substance on the behavior of an expansion type CNC for two working fluids, water and butanol. They found that two particle substances, $\mathrm{Ag}$ and $\mathrm{NaCl}$, did not affect the Kelvin diameter when butanol was used as the working fluid. However, the size of $\mathrm{NaCl}$ particles was overestimated by 2.5 times when water was used. Similar results were found by Porstendörfer et al. [14]. Kesten et al. [15] found different detection efficiency of the TSI CNC 3025 with butanol as a working fluid for $\mathrm{NaCl}$ and $\mathrm{Ag}$ particles. Kousaka et al. [16] found 
smaller, but still different results for $\mathrm{NaCl}$ and $\mathrm{Ag}$ particles. The brief description of results by Madelaine and Metayer [17] showed differences in $\mathrm{CNC}$ sensitivity for $\mathrm{NaCl}, \mathrm{V}_{2} \mathrm{O}_{5}$ and $\mathrm{H}_{2} \mathrm{SO}_{4}$ particles. The state of theoretical understanding is very limited, and therefore, experimental investigation of the effects of the nuclei composition on nucleation activation become important.

These preliminary works suggest the influence of nucleus composition and working fluid vapor. However, there is insufficient and inconsistent data for establishing a complete theoretical description of the phenomena.

\section{EXPERIMENTAL SETUP}

The basic components of the experimental system are a combustion chamber for carbon particle generation, a TMCNC for heterogeneous nucleation, $\underline{\underline{\text { and }}}$ a Differential Mobility Analyzer (DMA), and a conventional eondensationalCondensation Nuclei Counter (CNC)

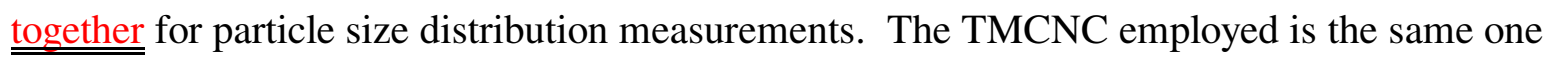
used in the study of Hopke et al. [18 $\underline{\underline{18}}$ and Mavliev et al. [19]. More detailed information is given in the following subsections.

\section{Particle generation}

Carbon particles, which are used as existing nuclei for the heterogeneous nucleation, were generated by a combustion process. The method theis same as described in Lee [20], and is similar to that of $\mathrm{Li}$ and Hopke [21]. The particles were produced by burning natural gas using a Bunsen burner. Filtered clean dilution air was introduced to keep the generated particles from coagulating in the chamber. The minimum particle size generated in the combustion process is not known and particles smaller than $6 \mathrm{~nm}$ (see next section) were not observable but are presumed present. The generated and measured carbon particles on average had a geometric mean of $9.9 \mathrm{~nm}$ with geometric standard deviation (GSD) of 1.33. The average concentration of the carbon particles at the mean diameterwasdiameter is about 225 particles $/ \mathrm{cm}^{3}$, equivalent to 7175 particles $/ \mathrm{cm}^{3}$ as $\mathrm{dN} / \mathrm{d} \log \mathrm{Dp}$ at that particle size. 


\section{| Text Moved Here: 1}

\section{Heterogeneous nucleation}

For examiningTo examine the heterogeneous nucleation, a modified TMCNC [16, 17] was used. As shown in Figure 3, the TMCNC consisteds of three parts: saturator, mixer, and condenser. All three parts of TMCNC wereare machined from blocks of aluminum alloy that alloweds $\underline{\underline{\underline{s}}}$ uniform temperature distribution within the block. An outer Teflon shell provideds insulation for the heated parts [16]. The temperatures of the heated parts separately by a circuit board and a data acquisition system (5500MF from ADAC corp.) with an accuracy of $\pm 0.2{ }^{\circ} \mathrm{C}$ while the temperature of the condenser was maintained at $20^{\circ} \mathrm{C}$ by a circulating water bath. A digital thermometer (model HH 12 from OMEGA Engineering, Inc.) was used as an additional reference for the temperature.

The TMCNC hads two chambers of equal size in the saturator of equal size. Flows from these two chambers wereare connected before passing through the mixer in Figure 3. One saturator chamber (so-called "wet" chamber) eothldcan be filled with a working fluid of 15-20 $\mathrm{cm}^{3}$ by volume of a working fluid while the other chamber ("dry") same temperature $[16,17]$. The degree of supersaturation flows passing through these two chambers while maintaining a constant total flow.

After these two coaxial flows are turbulently mixed in the mixer, they directed to the condenser. The residence time of particles in the condensation tube absis 2 seconds at a flow rate of $1.4 \mathrm{lpm}$. The actual residence time may have-been somewhat shorter because of the turbulent jet flow structure at the entrance of the condenser. However, it asis sufficient for particle growth [28] $]^{-}$

By changing the flow ratio as well as temperature of the saturator, the TMCNC produceds different supersaturation ratios. The flow rate coming from the saturator was $0.4 \mathrm{lpm}$, which resultsin $1.4 \mathrm{lpm}$ of flow to the DMA with the aerosol stream of $1.0 \mathrm{lpm}$. The wet flow and dry flow out of $0.4 \mathrm{lpm}$ of saturator flow shown in Figure 3. The output of the TMCNC is then directed into the size measurement $\underline{\underline{\text { system. }}}$.

\section{End Of Moved Text}


Size Selection

A long DMA (TSI model 3071) polydisperse aerosol and sheath air stream were 1.4 and $14 \mathrm{lpm}$, respectively. For this experimental setup, the DMA was practical for the selection of $6 \mathrm{~nm}$ and larger particles. It eoutdcan be used for smaller sizes, but there are high diffusional losses in the inlet and tubing up to the top of the system. As part of the DMA, a radioactive charger with a source of ${ }^{85} \mathrm{Kr}$ is used to impart a low charge distribution. A potential concern in these experiment would be the production of particle through ion-induced nucleation. $\mathrm{A}{ }^{85} \mathrm{Kr}$ source was used because earlier work had suggested it was less likely to produce additional particles [22]. Tests were run of the system with no generated particles to ensure that no ion-induced or homogeneous nucleation occurred at the vapor pressures of the working fluids used in these experiments.

In order to examine existence of generated carbon particles smaller than $6 \mathrm{~nm}$, a SMEC and a nano DMA were used. The SMEC (Spectromètre de MobillteMobilité Electriqué Circulaire), the inward radial flow mobility analyzer, was developed by Pourprix and Daval [23]. Studies by Mesbah et al. [24] showed that is it is effective at separating particles down to 1 nm. A nano DMA (TSI model 3085) can also separate down to $1 \mathrm{~nm}$ particles [25]. Using the SMEC with an ultrafine CNC (TSI model 3025 UCPC), size distributions of particles less than 6 nm were measured. These measurements shed more than $100 \%$ ofshow that particle concentrations for a given size varies greatly with the standard deviation ofs in the particle concentrations in the size distributions. Therefore, partieles were more than $100 \%$. The nano DMA along with the CNC showed fluctuations of the particle concentrations from 0 to hundreds of particles $/ \mathrm{cm}^{3}$. Due to the variation, particle sizes less than $6 \mathrm{~nm}$ were not tusedmeasured for heterogeneous nucleation analysis. This result means that the total number of particles detected will increase when carbon particles smaller that $6 \mathrm{~nm}$ are activated and nucleate droplets of working fluid that then grow to detectable sizes. This effect is a limitation to the measurements which is discussed below.

\section{Particle detection}

The ultrafine CNC (TSI model 3025 UCPC) was used to measure number concentration of nanometer particles extracted from the DMA. The combination of the CNC and the 
PMA DMA is the SMPS system used for obtaining size distributions. The TSI model 3025 enablets the measurement of particles of $3 \mathrm{~nm}$ diameter and larger at concentrations of $10^{-3}-10^{4}$ particles $/ \mathrm{cm}^{3}[26,27]$. The detection limit can reach $2-3 \mathrm{~nm}[25,28,29,30,31]$. $^{-}$

For heterogeneous nucleation, the long DMA and the UCPC were used as a SMPS

| system. The SMPS system alloweds the measurement of particles having $200 \mathrm{~nm}$ in size and smaller. In order to measure size distributions of grown particles of $200 \mathrm{~nm}$ or larger in size, a Laser Aerosol Spectrophotometer-X (PMS LAS-X) was used. It has ascanning range of $90 \mathrm{~nm}$ to $3.5 \mu \mathrm{m}[16,17\}$.

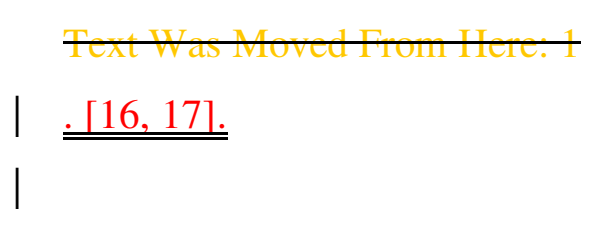

\section{Contact angle}

There was no information in the literature on the contact angles between carbon and working fluids, one of the important parameters in heterogeneous nucleation. Therefore, measurements of the contact angle were performed with a goniometer (Krüss Gmbh model ACAMS-40).

The four working fluids were dropped on a glass plate (Yissum Research Development Co.) on which carbon film was coated. Then, the macroscopic contact angles were measured. The measurements for DBP was performed at room temperature. For octadecane, octadecanol, and octadecanoic acid, the plate, the fluid, and the area, in which the measurements were performed, were heated above their melting points by a heat lamp during the measurements as necessary. The melting points $\underline{\underline{\text { are }}}$ 301, 331 and $343 \mathrm{~K}$ for octadecane, octadecanol and octadecanoic acid, respectively. Due to the different size of the droplets of the fluids and the different temperatures, the measured contact angles varied by 2 degree $\left(^{\circ}\right)$. The measured values are in Table 1.

\section{Temperatures for supersaturation ratio}

In order to obtain supersaturation ratios for theoretical nucleation rates, temperatures in 
the mixer were measured using the digital thermometer mentioned before. The temperatures are listed with respect to the corresponding saturator temperatures in Table 2. For calculating saturation ratio, it is neeessary to consider-vapor loss in the mixer in the TMCNC $\underline{\underline{\text { is necessary to }}}$ be considered. However, there asis no method was available to estimate the vapor loss in the turbulent flow regime in the mixer. Thus, all of the supersaturation ratios were calculated based on saturation vapor pressure-and should be eonsidered as upper bound estimates.

\section{Properties of working fluids}

Four working fluids were used in these studies and their physico-chemical parameters are given in Table 3. These compounds were chosen to be similar in their thermodynamic properties such as vapor pressure while having differences in dipole moment and polarizability. Three of them have very similar molecular structure with the only difference being in the moiety at the end of the long $\mathrm{CH}$ chain.

\section{EXPERIMENTAL PROCEDURE AND DATA REDUCTION}

The generated carbon particles passed through the TMCNC for heterogeneous nucleation Then, the particles elassified are sorted by electrieal mobilitysize in the DMA. The number concentration of the selected particles are measured in the CNC. Using the information of the particle sizes from the DMA and the corresponding number concentrations from the CNC, size distributions were obtained. To ensure that there was no produetion of ion-indueed partieles in the radioaetive eharger, experiments were performed with no added partieles analogously to the procedure deseribed by Mavliev et at.[30]. With vapor present in the system but no partictes eoming from the generator, there was no appreciable prodtuetion of partictes in the size range of interestare obtained.

For a given condition of saturator temperature and flow rate, a series of size distribution measurements were performed. -For each condition, at least 3 measurement series were made. Size distribution curves for selected conditions were conditions were chosen for calculating the experimental heterogeneous nucleation rate. The corresponding geometric means and standard deviations are presented in Table 4 with correlation coefficients, $\mathrm{R}^{2}$. Almost all of the size distribution curves wereare well fit with a log- 
normal distribution. The smallest value of the squared correlation coefficient $\left(\mathrm{R}^{2}\right)$ is 0.97 .

\section{RESULTS AND DISCUSSION}

Figures 4 through 7 show the-shows measured size distributions. The error bars in the Figures show the standard deviations in the measurements. In Figures 4 to 7, the zeronaught partial pressure, $0 \mathrm{~Pa}$, denotes the condition where no working fluid was introduced into the mixer, which means that the filtered air passets $\underline{\underline{s}}$ only through the dry chamber. Thus, the measured size distributions at $0 \mathrm{~Pa} \underline{\underline{w a s}}$ just that of the carbon nuclei at each given temperature. Again, note that the presence of carbon particles smaller than $6 \mathrm{~nm}$ is probable, but they cannot be detected by the particle size analyzer. As the wet flow increases, the

| supersaturation ratio, $S$, roserises to initiate heterogenous nucleation and consequent particle growth.

Figure 4 shows the particle size distributions when DBP was used as the $\underline{\underline{\underline{a}}}$ working fluid. At a saturator temperature of $68{ }^{\circ} \mathrm{C}$, particle size distributions at $8.69 \mathrm{mPa}$ of partial pressure were almost the same as the source distribution as shown in Figure 4. When the partial pressure was increased to $17.3 \mathrm{mPa}$, however, the particle size distribution differeds from the source distribution. Comparing particle size distributions at $17 \underline{\underline{25}} .39 \mathrm{mPa}$ of partial pressure and $0 \mathrm{~Pa}$ (carbon source particles), it can be seen that some of the $8.4 \mathrm{~nm}$ and larger diameter carbon particles were $\underline{\underline{a r e}}$ activated and greow to bigger sizes, so that concentration of the remaining (inaetivatednonactivated) particles wereare fewer than that of carbon source particles in the same size range. Since the aetivation was aecelerated as $\underline{\underline{\text { largest carbon }} \text { particle-size inereasess are the }}$ first to be activated, the concentration difference becomes greater with increasing particle size | although carbon source particle concentrations above the size of $9 \underline{\underline{8}} .9 \underline{\underline{4}} \mathrm{~nm}$ decrease rapidly:

| From a size of $11.1 \mathrm{~mm}$, with increasing partial pressure of DBP. It should be noted that for all runs above about $15 \mathrm{mPa}$, there appears a population of particles which were not present in the initial carbon particle distribution. These are the activated and grown droplets of working fluid. To measure the heterogeneous nucleation rate, it is not these large particles that are important, since we do not know from what size particle they formed. The depletion of the initial carbon particle population distribution is what is measured. This depletion is the concentration difference tended to deerease. Itbetween the original source particle concentration 
and the final measured one at the higher partial pressure of working fluid.

The range of mobility diameters over which this measurement can be made is limited

because for a given supersaturation, there is a lower limit below which few carbon particles are activated and the population remains at the original value and an upper limit above which there are new particles generated by the activation of some of the smaller ones which have not grown out of the original measurement size range during passage through the CNC. The lower limit at $\underline{25.9 \mathrm{mPa} \text { is about } 8.4 \mathrm{~nm} \text { while the upper limit of measurement is at the minimum in the }}$ concentration versus mobility diameter at $10.5 \mathrm{~nm}$. For all sizes larger than this, even though with a lower concentration that the initial concentration of carbon particles, the actual count is a combination of nonactivated initial carbon particles and activated smaller particles which grow into this size ramge. This means that the concentrations ineludedare contributed by particles that greow by vapor condensation after activation, as well as by inactivated particles. Because of the increased number of grown particles, the number concentration of the particles having 14.9 $\mathrm{nm}$ in diameter reacheds almost the same concentration as that of the source particles. Then, the particle concentrations becaome greater than the source distribution in bigger particle sizes with a long tail.

At a partial pressures of $25 \mathrm{DBP}$ of $17.9 \underline{\underline{\mathrm{DPa}}} \mathrm{m}$ or higher, the initial activation sizes decreaset. The higher wet flow rate the processes of nucleation and growth, so that the grown particle size becomes larger. As shown in Figure 4, the particle size distribution curves moved to largerbigger size and higher concentrations as the partial pressure roserises by increasing vapor flow. The tail of high concentrations of larger particles was observed from the presumed large concentrations of initial nucleation below $6 \mathrm{~nm}$ where not observable in the initial source concentration profile at $0 \mathrm{mPa}$ working fluid pressure.

When other working fluids, octadecane, octadecanol, and octadecanoic acid, ereare used, the first mode of the particle size distributions (Figures 5 through 7) for heterogeneous nucleation showed the same activation patterns as DBP with respect to partial pressure, which increaseds with the wet flow rates. Initial activation size and particle concentration decreased as the wet flow rate increased.

\section{Heterogeneous nucleation}


Using the concentrations from the fitted log-normal curves, each experimental heterogeneous nucleation rate at a given size and condition

$\mid \quad J\left(\# / \mathrm{cm}^{3} \cdot s\right)=\frac{\left(C_{@ P=0 P a}-C_{@ P=x P a}\right) \times Q}{V_{\text {mixer }}}$

where $\underline{\underline{\underline{2}}} \mathrm{C}_{@ \mathrm{P}=0 \mathrm{~Pa}}$ and $\mathrm{C}_{@ \mathrm{P}=\mathrm{xPa}}$ are the number concentrations $\left(\# / \mathrm{cm}^{3}\right)$ when partial pressures are at 0 and $\mathrm{x} \mathrm{Pa}$, respectively, $\mathrm{Q}$ is the flow rate through the mixer, $1.4 \mathrm{lpm}$, and $\mathrm{V}_{\text {mixer }}$ is the volume of the mixer, $0.8 \mathrm{~cm}^{3}$. When the size distributions show more than one mode, the second and the third modes, which are related to particle growth, were eliminated for investigating heterogeneous nucleation. The calculated experimental nucleation rates are shown in Figures 8 to 11 . Figures 8,10 , and 11 show theoretical nucleation rates as well for comparison purpose.

Since octadecane has a macroscopic contact angle, $\theta$, of 0 degree and, the other two | angles, $\psi$, and $\varphi$ in Figure 2, are 0: i.e., the existing nucleus is placed inside of the liquid cluster with only one contact point as shown in Figure 12. Therefore, Fletcher's geometric factor, $\mathrm{f}(\mathrm{m}, \mathrm{x})$ needs to be corrected for octadecane.

When $x\left(=a / r^{*}\right)>1$, with $\mathrm{m}(\cos \theta)=1$ in Equation (6), $g=(1-x)$. Consequently, $f(m, x)$ becomes 0. Then, the Gibbs free energy in Equation (5) also becomes 0. If $x=1, g=0$. Then, $\mathrm{f}(\mathrm{m}, \mathrm{x})$ in Equation (6) is not valid.

Considering the case of $\mathrm{x}$ smaller than 1 as shown in Figure $12, \mathrm{f}(\mathrm{m}, \mathrm{x})$, needs to be replaced by the ratio of the actual volume occupied by vapor to the critical cluster volume, $v(\theta)$ $\equiv\left(\mathrm{r}^{* 3}-\mathrm{a}^{3}\right) / \mathrm{r}^{* 3}$. In this case, instead of Equation (5) the critical Gibbs free energy becomes:

$\Delta G^{*}=\frac{16 \pi \gamma_{g l}^{3}}{3\left(\Delta G_{v}\right)^{2}} v(\theta)$

The critical Gibbs free energy for octadecane based on Fletcher's theory is $3.3 \times 10^{-19} \mathrm{~J}$ or higher for a carbon particle while values of $\mathrm{k}_{\mathrm{B}} \mathrm{T}$ are about $4.2 \times 10^{-21} \mathrm{~J}$. Thus, the exponential term, $\exp \left(-\Delta \mathrm{G}^{*} / \mathrm{k}_{\mathrm{B}} \mathrm{T}\right)$, in Equation (7) becomes $1.0 \times 10^{-34}$ or smaller. Since the calculated prefactor,

$\mid \frac{s(\theta)}{\sqrt{v(\theta)}} \sqrt{\frac{2 \Omega^{2} \gamma}{\pi m_{1}}} f_{1 \text { het }} f_{1}\left\{1+\left(n_{\text {hom }}^{*}\right)^{-1 / 3}\right\}^{2}$, 
in the-heterogeneous nucleation rate equation does not exceed $10^{7}$ particles $/ \mathrm{cm}^{3} \mathrm{~s}$, the calculated nucleation rate is $3.8 \times 10^{-28}$ particles $\mathrm{cm}^{-3} \mathrm{~s}^{-1}$, which is close to 0 particles $\mathrm{cm}^{-3} \mathrm{~s}^{-1}$. This calculation suggests that heterogeneous nucleation is almost impossible. However, the experiments show that particles were activated as seen in Figure 9.

For DBP, most of the Gibbs free energy values calculated by Fletcher's theory fall in the range of $10^{-20}$ and $10^{-21} \mathrm{~J}$, which give values of nucleation rates of $1.4 \times 10^{4}$ and $1.2 \times 10^{5}$ particles $\mathrm{cm}^{-3} \mathrm{~s}^{-1}$, respectively. When the supersaturation ratio is higher than 5 , i.e, , for the conditions of 25.9, 34.5, and $51.7 \mathrm{mPa}$, their calculated nucleation rates by Fletcher match well with the experimental values as shown in Figure 8. There are about two orders of magnitude difference between the theoretical and the experimental nucleation rates hireh is reasonable given thethat could be caused by uncertainties in Sthe prefactor. When $\mathrm{S}$ is less than 5, however, Fletcher's theory shows large differences from the experimental results as seen-in Figure 8: for the condition of $17.3 \mathrm{mPa}$.

When octadecanol and octadecanoic acid vapor were used for heterogeneous nucleation, the theoretical results are well matched with the experimental results for most conditions as shown in Figures 10 and 11. The differences caused by the prefactor are even smaller than those for DBP with the differences in the range of 1 order of magnitude.

For calculating heterogeneous nucleation, the-carbon nucleus and monomer shapes were assumed to be spherical. Examination of this assumption may help explain some of the observed discrepancy between the experimental results and the theoretical prediction. The shape of carbon particles and monomers was assumed to be spherical. di Stasio et al. [32] suggested that carbon particles generated by combustion process are likely to have a fractal shape. This shape may give more contact area than a spherespherical shape. Since a vapor molecule has a long earbonain of $\mathrm{C}-\mathrm{C}$ bond, thereit may behave steric hindrance with other molecules when it makes contact with a carbon particle. Therefore, the actual number of molecules having direct contact with a carbon particle could be different from the calculated. Streh differenes $\underline{\underline{\underline{t}}}$ will affect the geometrical factors, $f(m, x)$ and $v(\theta)$ in Equations (5) and (9), respectively. In order to obtain the actual number concentration affecting the geometrical factor, further studies are needed. 


\section{Particle growth}

As shown in Figures 4 through 7, the particle size distributions hatve a $2^{\text {nd }}$ and sometimes a $3^{\text {rd }}$ mode. The grown particle sizes hatve diameters of the order of $100 \mathrm{~nm}$ as summarized in Table 4. For octadecane, Figure 5 shows that few particles greow into the particle size range of $20 \mathrm{~nm}$ to $100 \mathrm{~nm}$. In case of octadecanol and octadecanoic acid as shown

| in Figures 6 and 7, respectively, the size distributions show that large particles hadve even higher number concentrations than those with DBP vapor. This increase may be the result of the interactions between hydrophilic functional groups, $-\mathrm{OH}$ and $-\mathrm{COOH}$, and large amount of water vapor produced by the combustion process for particle generation.

When DBP is used for working fluid, the grown particles showed two modes in the size

| distributions in Figure 4. The second mode asis not found with octadecanol and octadecanoic | acid as shown in Figures 6 and 7. The third mode with DBP wasis in the size range of greater than $35 \mathrm{~nm}$ where the second modes with other vapors were found. For the reason, further study of this particle growth is required.

For the second and/or third modes, i.e., for grown particle size distributions, shown in Figures 4 through 7, geometric means and the number concentrations of the particles tended to | increase as the wet flow rates were raised, which moredtucesults in introducing more vapor into the mixer, at a given temperature. For the case of octadecane, however, this relationship is not obvious.

All of the activated and grown particles were measured in the size range of up to $3.5 \mu \mathrm{mm}$. The number concentrations measured using SMPS for smaller particles, and LAS-X for larger particles than $100 \mathrm{~nm}$ in size are shown in Table 5 along with the number concentration of source carbon particles. Table 5 shows that total number concentrations of the remaining (inactivated) and grown particles are higher than that of carbon source particles with an exception of $106 \mathrm{mPa}$ of octadecane vapor pressure. The higher number concentration may be the result of fluctuations in the number concentration of carbon source particles especially at low partial vapor pressure of each vapor. However, at high partial vapor pressure, the measured total number concentrations are more than 5 times higher than the apparentcarbon source particle concentrations. This means that either some particles were generated from additional nucleation and/or growth processes other than those related to carbon particles of $6 \mathrm{~nm}$ or larger, and 
contribute to the total concentrations.

In order to examine whether any new particles could be generated by unary, and/or binary nucleation, nucleation rates were calculated. For the unary nucleation of the working fluids' vapor, the calculated Gibbs free energies are too high: the lowest energies for DBP, octadecane, octadecanol, and octadecanoic acid are, respectively, $1.1 \times 10^{-18}, 3.3 \times 10^{-18}, 4.0 \times 10^{-19}$, and $5.3 \times 10^{-19} \mathrm{~J}$ while $\mathrm{k}_{\mathrm{B}} \mathrm{T}$ is about $4.0 \times 10^{-21} \mathrm{~J}$. -The resultingconsequent nucleation rates are almost 0 . Thus, unary nucleation based on theory is not likely to occur.

Next, binary nucleation of the working fluid vapor and water vapor, produced by combustion process, was examined. In order to use the conceptual framework of Kulmaula and Viisanen [33], it is necessary to determine the virtual monomer volume :

$$
\Omega=(1-X) \Omega_{a}+X \Omega_{b},
$$

where $\Omega_{\mathrm{a}}$ and $\Omega_{\mathrm{b}}$ are, respectively, a working fluid monomer and a water monomer volume, and $\mathrm{X}$ is the water vapor fraction. Parameters for the calculations, molecular weight, density, vapor pressure, and surface tension of water, are provided in Table 6. The $\underline{\underline{W}}$ ater vapor pressure wasis $3.5 \mathrm{kPa}$ while vapor pressure of working fluids asis at most $4.5 \times 10^{-2} \mathrm{~Pa}$. Although $\Omega_{\mathrm{a}}$ is about 15 times of $\Omega_{b}$, the number of water vapor molecules in the virtual monomer dominant that water vapor mole-fraction wasis close to 1 . Thus, the binary nucleation is equivalent to homogeneous nucleation of water.

The aerosol stream was saturated with water vapor at $300 \mathrm{~K}$. Then, it cooled down to 293.15 K in the condenser of the TMCNC. -Since $\mathrm{S}$ is only 1.5 , the corresponding Gibbs free energy is $5.3 \times 10^{-18} \mathrm{~J}$ while $\mathrm{k}_{\mathrm{B}} \mathrm{T}$ is $4.0 \times 10^{-21} \mathrm{~J}$. Therefore, unary nucleation of water vapor is not possible.

For octadecane, octadecanol, and octadecanoic acid, the sublimation vapor pressure $\mathrm{P}$ (Pa) at a given temperature $\mathrm{T}(\mathrm{K})$ is calculated with the Clausius-Clapeyron equation:

$$
p=p^{*} \exp \left\{-\frac{\Delta H_{s u b}}{R}\left(\frac{1}{T}-\frac{1}{T^{*}}\right)\right\}
$$

where $\mathrm{p}^{*}$ is the saturation vapor pressure at melting point, $\mathrm{T}^{*}, \Delta \mathrm{H}_{\text {sub }}$ denotes the enthalpy of sublimation, and $\mathrm{R}$ is gas constant. Saturation vapor pressures of the working fluids at their melting points, and the enthalpies of vaporization are summarized in Table 7. 
| Since neither theoretical unary nucleation of the working fluids or water occur, the observed nucleation can be explained only by consideration of the ntreleation and grof of additional partielesparticle source. As mentioned earlier, particles smaller than $6 \mathrm{~nm}$ were detected although the particle concentration values had more than $100 \%$ of standard deviations of more than $100 \%$ deviation. As shown in Figure 13, average standard deviation of | the measured carbon source particle concentrations using model 3071 DMA wereare approximately $50 \%$ over all of the size range with $73 \%$ for $6.0 \mathrm{~nm}$ particles. With extrapolation

| of the extrapolating error estimates $\underline{\underline{\text { bars }}}$ to smaller particles, $6.0 \mathrm{~nm}$ or smaller particles are likely to exist. These particles may be the additional source-of grown partietes that were observed.

When DBP, octadecanol, and octadecanoic acid $\underline{\underline{\underline{a r e}}}$ used asfor working fluids, the grown particle size and number concentration gradually increase with partial vapor pressure. Figure 14 shows the ratio of fluid's mass accumulated on particles to mass of the vapor delivered into system. If the working fluids are the only source of the vapor supplied for heterogeneous nucleation and, especially, for particle growth, then the accumulated vapor fraction becomes | constant at higher pressures because the supersaturation substantially higher than the critical supersaturation and the growth then depends linearly on pressure of the condensable | vapor $[30\}$ (Mavliev et al., 2002). Above a certain vapor pressure, Figure 14 shows that the | accumulated liquid ratio increaseds $\underline{\underline{\underline{s}}}$ rapidly with increasing pressure. The ratio

| up to 0.8 . flConcerning vapor loss caused by condensing on the condenser wall, it is concluded that water vapor is likely to be involved in the growth process.

DBP, octadecanol, and octadecanoic acid have at least one hydrophilic functional group, ketone, hydroxyl, and carboxilic acid group, respectively. Water vapor could interact with these groups. There $\underline{\underline{\underline{i s}}}$ a considerable amount of water vapor ith a partiat, $1.2 \mathrm{kPa}$ in pressure-of $1.2 \mathrm{kPa}_{\underline{\underline{2}}}$ available that can directly interact with the condensed fluids. For a highty hydrophobie material like-octadecane, these interactions not likely because octadecane is a hydrophobic substance. In order to qualify and quantify the hypotheses in this study, further studies will be necessary.

\section{CONCLUSIONS}

Experimental heterogeneous nucleation rates on combustion carbon particles were 
measured for selected working (condensing) fluids using a TMCNC and compared with a theoretical rates based on Fletcher's (classical) heterogeneous nucleation theory. The experimental rates were found to differ from the theoretical values with the differences being more than ten orders of magnitude for DBP, and hundreds of orders of magnitude for octadecane. Consideration of homogeneous and binary nucleation at the low supersaturations of this study cannot explain the observed nucleation rates. We cannot explain the gap between the experimental measurements and the Fletcher theory for octadecane. There may be nanoscale interactions, activation of smaller than expected particles or multiple nanoparticle interactions that occur between the organic species, carbon particles, and working vapor. These speculations do not explain the discrepancy between theory and experiment. Further studies are will be necessary to examine these hypotheses.

\section{Acknowledgments}

This work is supported by US Environmental Protection Agency under grant R826654. We acknowledge the useful discussions of these results with Professor Michael Anisimov of Clarkson University and Dr. Vladimir Smorodin of Mose State University.

\section{References}

1. Peters, A., Wiehmann, H. E., Tueh, T., Heinrieh, J., and Heyder, J. Am. J. Respir. Erit. Care 1997, 155, 1376-1383 (1997)-Seaton, A., MacNee, W., Donaldson, K., and Godden, D. Lancet, 1995, 345, 176-178 (1995).

2. Kim, S., JaquesPeters, P. A., ChangWichmann, M., Froines, J. R., and Sioutas, C.

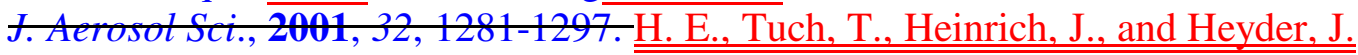
Am. J. Respir. Crit. Care Med. 1997, 155, 1376-1383 (1997).

3. -Kim, S., Jaques, P. A., Chang, M., BaroneFroines, FJ. R., Xiong, C., Friedlander, S. K., and Sioutas, C. J. Aerosol Sci., 2001, 32,1299-1314.1281-1297.

4. Sioutas, C., Koutrakis, P. Aerosol Set. Fechnol., 1996, 25, 424-436.KKim, S., Jaques, P. A., Chang, M., Barone, T., Xiong, C., Friedlander, S. K., Sioutas, C. J. Aerosol Sci., 2001, 32,1299-1314.

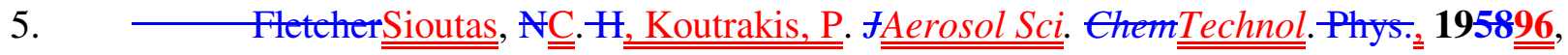

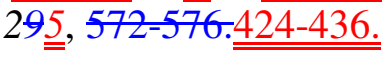




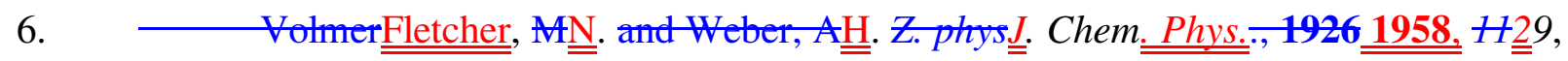
277-301. $\underline{\underline{572-576}}$.

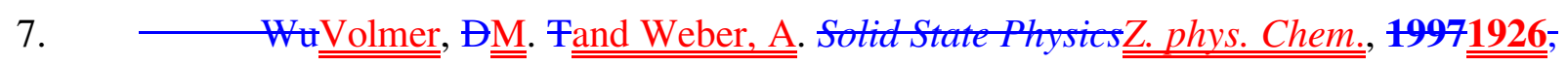
$50 \underline{\underline{119}}, \underline{37-187.277-301 .}$

8. VolmerWu, D. T. Solid State Physics, M., Z. Elektrehem.1929 1997, 350, $555=$ $561 . \underline{\underline{37-187 .}}$

9. Volmer, M., Z. Elektrochem. 1929, 35, 555-561.

10. White, L. R. (1977) J. Chem. Soc. Faratay Trans. I, 1977, 73, 390-398.,Fletcher, N. H. (1969) The Physics of Rainclouds. Cambridge University Press, Cambridge.

11. White, L. R. (1977) J. Chem. Soc. Faraday Trans. I, 1977, 73, 390-398.

12. Helsper, C. and Niessner, R.. J. Aerosol Sei., 1985, 16, 457-461.9Friedlander, S. $\underline{\underline{\text { K. And Lippmann, M. (1994) Revising the Particulate Ambient Air }}}$ Quality Standard. Environ. Sci. Technol., 28:148A-150A.

13. Porstendörfer, J., Seheibel, H. G., Pohl, F. G., Preining, O., Reiseh1, G., and Wagner P. E. Aerosol Sei. Technot. 1985, 4, 65-79. Helsper, C. and Niessner, R.. J. Aerosol Sci., 1985, 16, 457-461.

14. Kesten, J., Reineking, A., andtPorstendörfer, J.(1991), Scheibel, H. G., Pohl, F. G., Preining, O., Reischl, G., and Wagner P. E. Aerosol Sci. Technol..., 1991포,

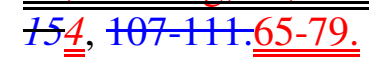

15. Kousaka Y., Okuyama K., and Niida T. in Aerosols (Ed. Liu, B., Pui, D., and Fissan, H.). Elsevier, NY, 1984, 51-54.1Kesten, J., Reineking, A., and Porstendörfer, J. (1991) Aerosol Sci. Technol., 1991, 15, 107-111.

16. Madeline, G. and Metayer, Y. J. Aerosol Sei., 1980, 11:358. Kousaka Y., Okuyama K., and Niida T. in Aerosols (Ed. Liu, B., Pui, D., and Fissan, H.). Elsevier, NY, 1984, 51-54.

17. Hopke, P.K., Lee, Đ.-W., Marliev, R., and Wang, H.-C. (2090) in Nucteation and Atmospheric Aerosols 2000: $15^{\text {th }}$ Int'l Conf. (Ed. Hale, B. N. and Kulmala, M.). Elsevier Seienee Ltd., Oxford, 2000, 1394tatine, G. and Metayer, Y.J. Aerosol Sci., 1980, 11:358.

18. Mavliev, R.,Hopke, P. K., Lee, D.-W., Mavliev, R., and Wang, H.-C., Lee, D.W. Aerosol Sei. Technol., 2001, 35, 586-595.1(2000) in Nucleation and Atmospheric Aerosols 2000: $15^{\text {th }}$ Int'l Conf. (Ed. Hale, B. N. and Kulmala, M.). Elsevier Science Ltd., Oxford, 2000, 139-142. 
19. Lee, Đ.-W. (2002) Ph.Đ. thesis, Clarkson University.eMavliev, R., Hopke, P. K., Wang, H.-C., Lee, D.-W. Aerosol Sci. Technol., 2001, 35, 586-595.

20. Ei, W., HopkeLee, PD.-W. K(2002) Ph.D. Aerosol Sei. Technot., 1993, 19, 305316.thesis, Clarkson University.

21. teong, K.H., Hopke, P.K., Sttke1, J.J. J. Aerot Set. 1983, 14, 23-27t, W., Hopke, P. K. Aerosol Sci. Technol., 1993, 19, 305-316.

22. Pourprix, M. and Daval, J. in Aerosols: Seience, Industry, Heatth and Enviromment (Proc. $3^{\text {rd }}$ International Aerosol Conf., Kyoto, Japan), vol. II(Ed. Mastuda, S. and Takahashi, K.), Pergamon Press, Oxford 1990, .w Leong, K.H., Hopke, P.K., Stukel, J.J. J. Aerosol Sci. 1983, 14, 23-27.

23. Mesbah, B., Fitzgerald, B., Hopke, P. K., andPourprix, M. Aerosol Sei. Technot., 1997, 27, 381-393.

and Daval, J. in Aerosols: Science, Industry, Health and Environment (Proc. $3^{\text {rd }}$ International Aerosol Conf., Kyoto, Japan), vol. II (Ed. Masuda, S. and Takahashi, K.), Pergamon Press, Oxford 1990,

24. Chen, D.-R., Pui, D.Y.H., Hummes, D., Fissan, H., Quant, F. R., and Sem, G.J. J. A Sei., 1998, 29, 497-509. Mesbah, B., Fitzgerald, B., Hopke, P. K., and Pourprix, M. Aerosol Sci. Technol., 1997, 27, 381-393.

25. Stolzenburg, M. R., MeDermott, W. T., and Sehwartz, AChen, D.-R., Pui, D. Y.

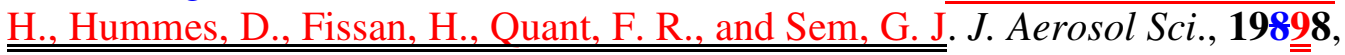
+29, 1015-1018.497-509.

26. -Stolzenburg, M. R.and MeMury, P. H., Aerol Set. Tech. 1991, 14, 48-65., McDermott, W. T., and Schwartz, A. J. Aerosol Sci., 1988, 19, 1015-1018.

27. MeDermott, W.T., Oekovie, R.C., and-Stolzenburg, M. R. and McMurry, P. H., Aerosol Sci. Fectotech.; 1991, 14, 278-287.48-65.

28. OkumaMcDermott, KW.T., KotsakaOckovic, ¥R.C., and

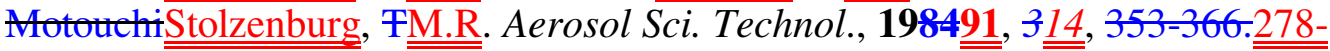
$\underline{\underline{287 .}}$

29. Mavliev, R. and Wang, H.-C. J. Aerol Set., 2000, 31, 933-944.40kuyama, K., Kousaka, Y., and Motouchi, T. Aerosol Sci. Technol., 1984, 3, 353-366.

30. -Mavliev, R. and Wang, H.-C. Atmospheric Res $\underline{\underline{\underline{J} \text {. Aerosol Sci. }}} . \mathbf{2 0 0 2 0}$, 62 $\underline{\underline{31}}$, 303= 314.933-944.

31. Mavliev, R. Atmospheric Res. 2002, 62, 303-314. 
32. Kulmala, M. and Viisanen, Y., Laaksonen, A. J. Aerot Sei., 1991, 22, S97= S100.di Stasio, S., Konstandopoulos, A. G., and Kostoglou, M. J. Coll. Intf. Sci., $\underline{\underline{2002}, 247,33-46 .}$

33. Kulmala, M. and Viisanen, Y., Laaksonen, A. J. Aerosol Sci., 1991, 22, S97-S100. 
Table 1. Contact angles between carbon and working fluids.

\begin{tabular}{|c|c|}
\hline Working fluid & $\begin{array}{c}\text { Measured macroscopic contact angle }\left(^{\circ}\right) \text { between } \\
\text { carbon and the working fluid in air }\end{array}$ \\
\hline DBP & $7 \pm 2$ \\
\hline Octadecane & $15 \pm 2$ \\
\hline Octadecanol & $8 \pm 2$ \\
\hline Octadecanoic acid & 0 \\
\hline
\end{tabular}

Table 2. Mixer temperatures for different conditions of saturator temperature.

\begin{tabular}{|l|c|c|c|}
\hline Saturator temperature $\left({ }^{\circ} \mathrm{C}\right)$ & 65 & 73.5 & 70.7 \\
\hline Mixer temperature $(\mathrm{K})$ & 303.9 & 306.3 & 305.5 \\
\hline
\end{tabular}


Table 3. Physico-chemical properties of ntelei and (for \#69-23) working fluids for calculating chemical interaction energy. 


\begin{tabular}{|c|c|c|c|c|}
\hline Properties & DBP & Octadecane & Octadecanol & $\begin{array}{c}\text { Octadecanoic } \\
\text { acid }\end{array}$ \\
\hline molecular weight (g/mol) & 278.3 & 254.5 & 270.5 & 284.5 \\
\hline boiling point $\left({ }^{\circ} \mathrm{C}\right)$ & 340.0 & 316.9 & 333.2 & 375.4 \\
\hline $\begin{array}{l}\text { supersaturation ratio } \\
\text { between } 70 \text { and } 32{ }^{\circ} \mathrm{C}\end{array}$ & 84.9 & 42.7 & 112 & 82.7 \\
\hline monomer volume $\left(\mathrm{m}^{-3}\right)$ & $4.5 \times 10^{-28}$ & $5.5 \times 10^{-28}$ & $5.4 \times 10^{-28}$ & $5.4 \times 10^{-28}$ \\
\hline \multirow{5}{*}{$\begin{array}{l}\text { density at } \mathrm{T}(\mathrm{K}) \\
\qquad\left(\mathrm{kmol} / \mathrm{m}^{3}\right)\end{array}$} & \multicolumn{4}{|c|}{, where the coefficients are below: } \\
\hline & $A=0.297$ & $\mathrm{~A}=0.241$ & $A=0.262$ & $A=0.264$ \\
\hline & $\mathrm{B}=0.251$ & $\mathrm{~B}=0.258$ & $\mathrm{~B}=0.265$ & $\mathrm{~B}=0.269$ \\
\hline & $\mathrm{C}=781.0$ & $\mathrm{C}=745.3$ & $\mathrm{C}=777.0$ & $\mathrm{C}=799.0$ \\
\hline & $\mathrm{D}=0.374$ & $\mathrm{D}=0.274$ & $\mathrm{D}=0.327$ & $\mathrm{D}=0.303$ \\
\hline \multirow{6}{*}{ vapor pressure at $\mathrm{T}(\mathrm{K})$} & \multicolumn{4}{|c|}{$\exp \left(A+\frac{\boldsymbol{D}}{T}+C \ln T+D T^{E}\right)$ with coeffic } \\
\hline & $\mathrm{A}=356.4$ & $\mathrm{~A}=129.2$ & $A=157.7$ & $A=124.7$ \\
\hline & $B=-24762$ & $B=-15072$ & $\mathrm{~B}=-18863$ & $B=-16598$ \\
\hline & $C=-51.17$ & $C=-14.47$ & $C=-17.98$ & $C=-13.56$ \\
\hline & $\mathrm{D}=0.039$ & $\mathrm{D}=4.16 \times 10^{-18}$ & $\mathrm{D}=1.50 \times 10^{-18}$ & $\mathrm{D}=3.16 \times 10^{-18}$ \\
\hline & $\mathrm{E}=1.00$ & $\mathrm{E}=6.00$ & $\mathrm{E}=6.00$ & $\mathrm{E}=6.00$ \\
\hline \multirow[t]{3}{*}{ surface tension at $\mathrm{T}(\mathrm{K})$} & \multicolumn{4}{|c|}{$A\left(1-T_{r}\right)^{\left(B+C T_{r}+D T_{r}^{2}+E T_{r}^{3}\right)}$, where $\mathrm{T}_{\mathrm{r}}=\mathrm{T} / \mathrm{T}_{\mathrm{c}}$ with coefficients } \\
\hline & $A=0.060$ & $A=0.057$ & $A=0.055$ & $\mathrm{~A}=0.054$ \\
\hline & $\mathrm{B}=1.219$ & $\mathrm{~B}=1.409$ & $\mathrm{~B}=1.234$ & $\mathrm{~B}=1.147$ \\
\hline critical temperature $(\mathrm{K})$ & 781.0 & 745.3 & 777.0 & 799.0 \\
\hline dipole moment $(\mathrm{Cm})$ & $5.7 \times 10^{-30}$ & 0 & $5.4 \times 10^{-30}$ & $4.3 \times 10^{-30}$ \\
\hline polarizability volume $\left(\mathrm{m}^{-3}\right)$ & $4.6 \times 10^{-29}$ & $3.4 \times 10^{-29}$ & $4.2 \times 10^{-29}$ & $2.6 \times 10^{-29}$ \\
\hline
\end{tabular}


Equations and data are from physical and thermodynamic properties of pure chemicals (Daubert and Danner, 1996). 
। 
Table 4. Geometric means and standard deviations of log-normally fitted modes.

\begin{tabular}{|c|c|c|c|c|c|c|c|c|}
\hline \multirow{2}{*}{ Working fluid } & \multirow{2}{*}{$\begin{array}{l}\mathrm{P}_{\text {partial }} \\
(\mathrm{mPa})\end{array}$} & \multicolumn{2}{|c|}{$1^{\text {st }}$ mode } & \multicolumn{2}{|c|}{$2^{\text {nd }}$ mode } & \multicolumn{2}{|c|}{$3^{\text {rd }}$ mode } & \multirow{2}{*}{$\mathrm{R}^{2}$} \\
\hline & & $\mathrm{d}_{\mathrm{g}}(\mathrm{nm})$ & $\sigma_{g}$ & $\mathrm{~d}_{\mathrm{g}}(\mathrm{nm})$ & $\sigma_{g}$ & $\mathrm{~d}_{\mathrm{g}}(\mathrm{nm})$ & $\sigma_{\mathrm{g}}$ & \\
\hline \multirow{3}{*}{$\mathrm{DBP}$} & 17.3 & 8.74 & 1.12 & 17.42 & 1.74 & 92.37 & 1.62 & 0.99 \\
\hline & 25.9 & 8.23 & 1.17 & 24.82 & 1.49 & 118.16 & 1.78 & 0.97 \\
\hline & 34.5 & 7.36 & 1.07 & 27.77 & 1.56 & 151.40 & 1.84 & 1.00 \\
\hline \multirow{4}{*}{ Octadecane } & 51.7 & 6.78 & 1.04 & 35.09 & 1.78 & 187.67 & 1.66 & 1.00 \\
\hline & 106 & 8.56 & 1.24 & & & & & 0.98 \\
\hline & 159 & 7.90 & 1.16 & 81.79 & 2.46 & & & 0.98 \\
\hline & 215 & 7.63 & 1.09 & 134.95 & 2.08 & & & 0.98 \\
\hline \multirow{4}{*}{ Octadecanol } & 1.15 & 9.65 & 1.25 & & & & & 0.98 \\
\hline & 2.28 & 8.97 & 1.27 & 23.91 & 1.49 & & & 0.98 \\
\hline & 3.41 & 7.42 & 1.18 & 45.01 & 1.84 & & & 0.97 \\
\hline & 4.55 & 6.80 & 1.07 & 73.33 & 2.04 & & & 1.00 \\
\hline \multirow{2}{*}{$\begin{array}{l}\text { Octadecanoic } \\
\text { acid }\end{array}$} & 1.14 & 10.63 & 1.33 & 27.86 & 1.72 & & & 0.97 \\
\hline & 2.27 & 8.08 & 1.21 & 51.82 & 1.95 & & & 0.98 \\
\hline
\end{tabular}


Table 5. Total number concentrations of grown and source particles.

\begin{tabular}{|c|c|c|c|c|c|}
\hline \multirow[b]{2}{*}{ Working fluid } & \multirow{2}{*}{$\begin{array}{l}\mathrm{P}_{\text {partial }} \\
(\mathrm{mPa})\end{array}$} & \multicolumn{2}{|c|}{ total number concentration $\left(\# / \mathrm{cm}^{3}\right)$ of } & \multicolumn{2}{|c|}{ concentration $\left(\# / \mathrm{cm}^{3}\right)$ from } \\
\hline & & source particles & $\begin{array}{l}\text { inactivated and } \\
\text { grown particles }\end{array}$ & SMPS & LAS-X \\
\hline \multirow{3}{*}{ DBP } & 17.3 & \multirow{4}{*}{1933} & 2738 & 1447 & 23 \\
\hline & 25.9 & & 5790 & 3315 & 1592 \\
\hline & 34.5 & & 11763 & 4665 & 6807 \\
\hline \multirow{3}{*}{ Octadecane } & 51.7 & & 20001 & 2980 & 16962 \\
\hline & 106 & \multirow{2}{*}{1508} & 1179 & 102 & 8 \\
\hline & 159 & & 1518 & 398 & 364 \\
\hline
\end{tabular}




\begin{tabular}{|c|c|c|c|c|c|}
\hline & 215 & & 6519 & 184 & 5960 \\
\hline \multirow{4}{*}{ Octadecanol } & 1.15 & \multirow{4}{*}{1129} & 1135 & 50 & 0 \\
\cline { 2 - 4 } & 2.28 & & 2033 & 925 & 0 \\
\cline { 2 - 4 } & 3.41 & & 7865 & 6633 & 598 \\
\cline { 2 - 4 } & 4.55 & & 12205 & 10295 & 1869 \\
\cline { 5 - 6 } & 1.14 & \multirow{4}{*}{4741} & 9227 & 5141 & 48 \\
\hline \multirow{2}{*}{$\begin{array}{c}\text { Octadecanoic } \\
\text { acid }\end{array}$} & 2.27 & & 18665 & 14053 & 3992 \\
\hline
\end{tabular}


Table 6. Physical properties of water.

\begin{tabular}{|c|l|}
\hline $\begin{array}{c}\text { Properties } \\
\text { molecular } \\
\text { weight }(\mathrm{g} / \mathrm{mol})\end{array}$ & \multicolumn{1}{c|}{ Value or equation with coefficients } \\
\hline $\begin{array}{c}\text { density }\left(\mathrm{kmol} / \mathrm{m}^{3}\right) \\
\text { at } \mathrm{T}(\mathrm{K})\end{array}$ & $A+B\left(1-T_{r}\right)^{0.35}+C\left(1-T_{r}\right)^{2 / 3}+D\left(1-T_{r}\right)+E\left(1-T_{r}\right)^{4 / 3}$ \\
\hline $\begin{array}{c}\text { vapor pressure }(\mathrm{Pa}) \\
\text { at } \mathrm{T}(\mathrm{K})\end{array}$ & $\mathrm{A}=18.06, \mathrm{~B}=25.31, \mathrm{C}=66.17$, and $\mathrm{D}=-50.21$ \\
\hline
\end{tabular}




\begin{tabular}{|c|l|}
\hline $\begin{array}{c}\text { surface tension }(\mathrm{N} / \mathrm{m}) \text { at } \\
\mathrm{T}(\mathrm{K})\end{array}$ & $A\left(1-T_{r}\right)^{\left(B+C T_{r}+D T_{r}^{2}+E T_{r}^{3}\right)}$ \\
& $\mathrm{A}=0.1855, \mathrm{~B}=2.717, \mathrm{C}=-3.554$, and $\mathrm{D}=2.047$ \\
\hline critical temperature $(\mathrm{K})$ & 647.13 \\
\hline
\end{tabular}

Equations and Data are from physical and thermodynamic properties of pure chemicals (Daubert and Danner, 1998). 
Table 7. Summarized data for calculating sublimation vapor pressure.

\begin{tabular}{|l|c|c|c|}
\hline \multicolumn{1}{|c|}{ Fluid } & $\begin{array}{c}\text { vapor pressure }(\mathrm{Pa}) \\
\text { at melting point }\end{array}$ & melting point $(\mathrm{K})$ & $\Delta \mathrm{H}_{\text {sub }}(\mathrm{kJ} / \mathrm{mol})^{*}$ \\
\hline octadecane & 0.0337 & 301.33 & 153.0 \\
\hline octadecanol & 0.0280 & 331.05 & 187.4 \\
\hline octadecanoic acid & 0.0563 & 342.75 & 167.0 \\
\hline
\end{tabular}

* data are from the website of NIST (http://webbook.nist.gov/cgi/cbook.cgi). All of the other data are from physical and thermodynamic properties of pure chemicals (Daubert and Danner, 1998). 
Figure Captions

Figure 1. The spherical cap model for heterogeneous nucleation. The contact angle $\theta$ is determined by force balance of the surface tension $\gamma$ between the gas, liquid, and the substrate. $\mathrm{r}$ is the radius of the projected sphere.

Figure 2. Schematic representation of a liquid cluster on a spherical aerosol particle. $r$ : cluster radius, $\psi$ : contact angle, and a: radius of the spherical aerosol particle.

Figure 3. A modified TMCNC.

Figure 4. $\quad$ Particle size distributions with DBP at $73.5{ }^{\circ} \mathrm{C}$ of saturator temperature.

Figure 5. Particle size distributions with octadecane at $65{ }^{\circ} \mathrm{C}$ of saturator temperature.

Figure 6. Particle size distributions with octadecanol at $65{ }^{\circ} \mathrm{C}$ of saturator temperature.

Figure 7. Particle size distributions with octadecanoic acid at $70.7{ }^{\circ} \mathrm{C}$ of saturator temperature.

Figure 8. Heterogeneous nucleation rates with DBP at $73.5{ }^{\circ} \mathrm{C}$ of saturator temperature: lines with symbols denote experimental nucleation rates while series of only symbols are from calculations of Fletcher's theory.

Figure 9. Experimental heterogeneous rates with octadecane at $65{ }^{\circ} \mathrm{C}$ of saturator temperature. 
Figure 10. Heterogeneous nucleation rates with octadecanol at $65{ }^{\circ} \mathrm{C}$ of saturator temperature: lines with symbols denote experimental nucleation rates while series of only symbols are from calculations of Fletcher's theory.

Figure 11. Heterogeneous nucleation rates with octadecanoic acid at $70.7{ }^{\circ} \mathrm{C}$ of saturator temperature: lines with symbols denote experimental nucleation rates while series of only symbols are from calculations of Fletcher's theory, and only lines are ratios of the chemical interaction to Fletcher's heterogeneous nucleation energy.

Figure 12. Schematic view of critical liquid cluster containing a pre-existing nucleus inside: $\theta, \psi$, and $\varphi$ are 0 .

Figure 13. Carbon source particle size distribution.

Figure 14. The fractional ratios of each working fluids mass accumulated on carbon particles to total mass of each vapor pressure delivered into system with respect to partial vapor pressure. 